\title{
Possibility of the Heart Rate Variability Correction with a High Dose of Omega-3-polyunsaturated Fatty Acids in Patients with Acute Myocardial Infarction and Concomitant Type 2 Diabetes Mellitus
}

\author{
Aleksey G. Nikishin, MD, ScD; Timur A. Nurbaev, MD; Maksud S. Khasanov, MD; \\ Saodat Y. Abdullaeva, MD; Nodirbek T. Yakubbekov, MD
}

The Republican Specialized Center of Cardiology, Tashkent, Uzbekistan

\begin{abstract}
Aim: To evaluate the efficacy of a high dose (4g/day) of omega-3-PUFA on the heart rate variability (HRV) characteristics in patients with acute myocardial infarction (AMI) and Type 2 Diabetes Mellitus (T2DM)

Material and Methods: The study included 93 patients with AMI and concomitant T2DM during the first 48 hours from the onset of the disease. Group 1 comprised 40 patients, who received the standard therapy for AMI. Group 2 consisted of 53 patients, who, in addition to the standard treatment, in the absence of contraindications received omega-3-PUFA (4g/day) from the first day of therapy. All patients underwent Holter ECG monitoring on the first and seventh days of hospitalization.

Results: In the first 48 hours of AMI, a strong trend in reduction of SDNN value in the daytime and at night was marked in patients of both groups. There were no significant changes in HRV time-domain indicators during standard therapy in Group 1. In contrast, Group 2 was characterized by statistically significant increases in mRR and SDNN values in the daytime, as well as RMSSD and pNN50\%. This trend was also observed at night. In Group 2, Mo and HRV TI (in daytime and at night) also changed significantly compared to baseline.

Conclusion: In the patients with AMI and concomitant T2DM, there were significant changes in the main parameters of HRV that reflected the decrease in the activity of the parasympathetic nervous system and an increase in the activity of the sympathetic nervous system. Use of omega-3-PUFA in addition to standard therapy from the first hours of AMI allowed stabilization of the parasympathetic-sympathetic imbalance.
\end{abstract}

Keywords: acute myocardial infarction; type 2 diabetes mellitus; omega-3-polyunsaturated fatty acids.

\section{Introduction}

Current research has shown that the low parameters of the heart rate variability (HRV) are correlated with the risk of sudden death, even more than the parameters of the left ventricle ejection fraction or the quality of the ventricle arrhythmias during Holter ECG monitoring and physical tolerability [1]. The problem of correcting the reduced HRV remains to be solved [2]. However, the use of beta-blockers, angiotensin-converting enzyme inhibitors, and calcium antagonists may lead to the reduction of the cardiovascular death risk and increasing HRV parameters. On the other hand,

*Corresponding author: Aleksey G. Nikishin, MD, ScD. Chief of the Acute Myocardial Infarction Department, Republican Specialized Center of Cardiology. Tashkent, Uzbekistan.

E-mail:angdoc@yandex.ru the use of antiarrhythmic agents of classes I and III also leads to HRV reduction; nevertheless, applying of these drugs to correct reduced HRV in the acute period of myocardial infarction has an insufficient evidence base [3-6].

Consequently, the use of omega-3-polyunsaturated fatty acids (omega-3-PUFA) is the new strategy direction in research; accordingly, the aim of this study was to evaluate the efficacy of a high dose ( $4 \mathrm{~g} / \mathrm{d})$ of omega-3-PUFA on the HRV characteristics in patients with acute myocardial infarction (AMI) and Type 2 Diabetes Mellitus (T2DM).

\section{Material and Methods}

The study included 93 patients (73 males and 20 females) admitted to the hospital with AMI and concomitant T2DM during the first 48 hours from the onset of the disease. 
The study was approved by the Republican Specialized Center of Cardiology Ethics Committee. Written informed consent was obtained from each patient.

The patients were divided into two groups. The control group (Group 1) comprised 40 patients, who received the standard therapy for AMI, which included dual antiplatelet therapy (aspirin+clopidogrel), unfractionated heparin intravenously, beta-blockers (bisoprolol), statins (atorvastatin). The study group (Group 2) consisted of 53 patients, who, in addition to the standard treatment, in the absence of contraindications received omega-3-PUFA (Omacor, Abbot, USA) 4 grams per day from the first day of therapy. There were no percutaneous coronary interventions in either group. Exclusion criteria included severe respiratory and renalhepatic failure, malignancy, acute inflammatory diseases, the lack of a stable sinus rhythm (atrium fibrillation, paroxysmal supraventricular tachiarrythmias). In order to evaluate the state of the vegetative nervous system and HRV parameters, all patients underwent Holter ECG monitoring on the first and seventh days of hospitalization. Data processing and evaluation were performed by the CardioSens $+v 3.0$ program (HAI-Medica, Ukraine).

The state of the vegetative status of the patients was assessed by the following parameters:

- HRV time-domain indicators: SDNN, RMSSD, pNN50

- HRV frequency-domain indicators: LF, HF, LF/HF, TP

- HRV geometric indicators: IC, Mo, AMo, HRVTI.

These parameters were evaluated both in daytime and at night [1].

Results were statistically processed using the software package Biostat v4.03. Analysis of the distribution of values obtained was performed using the Kolmogorov-Smirnov test. For data with normal distribution, inter-group comparisons were performed using Student's t-test. 95\% Confidence Interval $(95 \% \mathrm{CI})$ for quantitative parameters also was applied. The Odds Ratio (OR) and $95 \% \mathrm{CI}$ were calculated with use of logistic regression. Taking into account that the distribution of the spectral parameters of HRV were expressed in absolute units independently on the order of normal distribution, the logarithm transformation of the spectral values (LN) was used to perform the analysis. For all types of analysis, the value of $\mathrm{P}<0.05$ was considered statistically significant.

\section{Results}

Both groups of patients were comparable according to their major clinical-demographic characteristics (Table 1). The average age of patients of Group 1 was $56.6 \pm 1.75$ (median: 56 years) and 56.3 \pm 1.0 (median: 57 years) for patients of Group 2. Among the patients in Group 2, there were more males $(88.7 \%)$ than females $(65 \%)(95 \%$ CI: $1.45-12.3 ; \mathrm{P}=0.01)$. There were no statistically significant differences in AMI in the incidence rate in relation to the place of localization and the presence of $\mathrm{Q}$ wave between groups. The average starting doses of drugs, which could affect the characteristics of HRV, were the same for both groups.

In the first 48 hours of AMI, according to our results, a strong trend in reduction of SDNN value in the daytime
(41.5 $\pm 1.15 \mathrm{~ms}$ in Group 1 and $38.4 \pm 1.42 \mathrm{~ms}$ in Group 2) and at night $(41.1 \pm 1.89 \mathrm{~ms}$ in Group 1 and $41.9 \pm 1.80 \mathrm{~ms}$ in Group 2 ) was marked in patients of both groups, which reflected an unfavorable prognosis [2].

Table 1.

Clinical-demographic characteristics of the patients

\begin{tabular}{|l|c|c|c|c|c|c|c|}
\hline \multirow{2}{*}{ Indicators } & \multicolumn{2}{|c|}{$\begin{array}{c}\text { Group 1 } \\
\mathrm{n}=40\end{array}$} & \multicolumn{2}{c|}{$\begin{array}{c}\text { Group } 2 \\
\mathrm{n}=53\end{array}$} & OR & $95 \%$ CI & $\mathrm{P}$ \\
\cline { 2 - 6 } & $\mathrm{n}$ & $\%$ & $\mathrm{n}$ & $\%$ & & & \\
\hline Age, years & \multicolumn{2}{|c|}{$56.6 \pm 1.75$} & \multicolumn{2}{|c|}{$56.3 \pm 1.0$} & & & 0.88 \\
\hline Me (95\%CI) & $56.0(53.2-60.0)$ & $57.0(53.2-59.4)$ & & \\
\hline Males & 26 & 65.0 & 47 & 88.7 & 4.22 & $1.45-12.3$ & 0.01 \\
\hline $\begin{array}{l}\text { Q-wave } \\
\text { anterior AMI }\end{array}$ & 9 & 22.5 & 16 & 30.2 & 1.42 & $0.58-3.84$ & 0.55 \\
\hline $\begin{array}{l}\text { Non-Q-wave } \\
\text { anterior AMI }\end{array}$ & 20 & 50.0 & 19 & 35.8 & 0.56 & $0.24-1.29$ & 0.25 \\
\hline $\begin{array}{l}\text { Q-wave } \\
\text { inferior AMI }\end{array}$ & 6 & 15.0 & 13 & 24.5 & 1.84 & $0.63-5.37$ & 0.39 \\
\hline $\begin{array}{l}\text { Non-Q-wave } \\
\text { inferior AMI }\end{array}$ & 5 & 12.5 & 3 & 5.7 & 0.42 & $0.09-1.87$ & 0.43 \\
\hline $\begin{array}{l}\text { History of } \\
\text { AMI }\end{array}$ & 10 & 25.0 & 9 & 17.0 & 0.61 & $0.22-1.69$ & 0.49 \\
\hline LV EF, \% & $57.0 \pm 1.66$ & $52.6 \pm 1.30$ & & $52.25-57.51$ & 0.22 \\
\hline
\end{tabular}

\section{Dynamics of the HRV time-domain indicators during the therapy}

In Group 1, there were no significant changes in HRV time-domain indicators during standard therapy (Table 2). The observed tendency to increased RMSSD parameters in daytime, and RMSSD and pNN50 at night, had no statistical significance; values of pNN50 indicators in daytime even diminished on the seventh day of therapy. In contrast, Group 2 , which received high doses of omega-3-PUFA in addition to the standard therapy was characterized by statistically significant increases in $\mathrm{mRR}(\mathrm{P}=0.002)$ and $\mathrm{SDNN}(\mathrm{P}=0.002)$ values in the daytime, as well as RMSSD $(\mathrm{P}=0.004)$ and pNN50\% $(\mathrm{P}=0.002)$, indicating increased activity of the parasympathetic nervous system. This trend was also observed at night, only with a difference concerning pNN $50 \%(\mathrm{P}=0.28)$, which was increased on the seventh day of therapy; however, these changes had a statistically significant character. In patients receiving omega-3-PUFA, the increase in RMSSD $(\mathrm{P}=0.04)$ appeared to be higher in statistical significance than in the control group.

\section{Dynamics of HRV frequency-domain indicators during therapy}

In Group 1, the spectral indicators analysis revealed a lack of the significant changes in TP, ULF, LF and HF values in daytime and at night during therapy. However, there was not a marked reduction of LF/HF indexes in daytime that showed reduction in activity of the sympathetic nervous system (Table $3)$.

In Group 2, no statistically significant changes in TP, ULF, VLF and LF values during daytime and night hours were found. Reduction of the LF/HF ratio was observed during both day and night; however, this reduction did not reach statistical significance. 
Table 2.

Changes in HRV time-domain indicators during the therapy

\begin{tabular}{|c|c|c|c|c|c|c|c|c|}
\hline \multirow{2}{*}{ Indicators } & \multicolumn{3}{|c|}{ Group 1, $\mathrm{n}=40$} & \multicolumn{3}{c|}{ Group 2, $\mathrm{n}=53$} \\
\cline { 2 - 9 } & admission & $7^{\text {th }}$ day & $\mathrm{P}$ & admission & $7^{\text {th }}$ day & $\mathrm{P}$ \\
\hline \multicolumn{7}{|c|}{ Day } \\
\hline mRR, MS & $853.4 \pm 20.3$ & $888.8 \pm 20.0$ & 0.22 & $839.9 \pm 18.3$ & $921.5 \pm 17.2$ & $0.002^{*}$ & 0.22 \\
\hline SDNN, MS & $41.5 \pm 1.15$ & $41.6 \pm 2.42$ & 0.97 & $38.4 \pm 1.42$ & $44.0 \pm 1.82$ & $0.02^{*}$ & 0.42 \\
\hline SDNNi, MS & $10.0 \pm 0.76$ & $9.51 \pm 0,73$ & 0.64 & $9.12 \pm 0.57$ & $10.5 \pm 0.94$ & 0.21 & 0.43 \\
\hline RMSSD, MS & $23.6 \pm 2.35$ & $26.6 \pm 2.77$ & 0.41 & $24.4 \pm 1.36$ & $33.8 \pm 2.88$ & $0.004^{*}$ & 0.08 \\
\hline pNN50,\% & $7.28 \pm 1.72$ & $6.10 \pm 1.55$ & 0.61 & $4.01 \pm 0.81$ & $7.16 \pm 1.03$ & $0.002^{*}$ & 0.56 \\
\hline \multicolumn{7}{|c|}{ Night } \\
\hline mRR, MS & $915.2 \pm 22.4$ & $970.0 \pm 26.0$ & 0.11 & $882.2 \pm 18.9$ & $1003.9 \pm 18.5$ & $0.000^{*}$ & 0.28 \\
\hline SDNN, MS & $41.1 \pm 1.89$ & $45.9 \pm 2.15$ & 0.10 & $41.9 \pm 1.80$ & $50.0 \pm 1.93$ & $0.003^{*}$ & 0.16 \\
\hline SDNNi, MS & $9.73 \pm 0.70$ & $10.3 \pm 0.90$ & 0.62 & $9.92 \pm 0.66$ & $11.7 \pm 0.99$ & 0.14 & 0.31 \\
\hline RMSSD, MS & $27.7 \pm 2.76$ & $30.3 \pm 3.14$ & 0.54 & $30.2 \pm 1.27$ & $39.0 \pm 2.77$ & $0.005^{*}$ & $0.04^{*}$ \\
\hline pNN50,\% & $3.96 \pm 2.44$ & $9.12 \pm 2.37$ & 0.13 & $7.73 \pm 1.89$ & $10.9 \pm 2.26$ & 0.28 & 0.59 \\
\hline
\end{tabular}

* - $p<0.05$ ( $m R R$ - average duration of all RR intervals, SDNN-standard deviation of all NN-intervals, RMSSD - square root from average sum of square differences between adjacent $N N$-intervals, pNN50 - proportion of interval between adjacent NN more than 50 ms.

Table 3.

Changes in HRV frequency-domain indicators during the therapy

\begin{tabular}{|c|c|c|c|c|c|c|c|}
\hline \multirow{2}{*}{ Indicators } & \multicolumn{3}{|c|}{ Group $1, \mathrm{n}=40$} & \multicolumn{3}{|c|}{ Group 2, n $=53$} & \multirow{2}{*}{$\mathrm{P}$} \\
\hline & admission & $7^{\text {th }}$ day & $\mathrm{P}$ & admission & $7^{\text {th }}$ day & $\mathrm{P}$ & \\
\hline \multicolumn{8}{|c|}{ Day } \\
\hline LN TP, MS $^{2}$ & $7.19 \pm 0.16$ & $7.19 \pm 0.17$ & 1.0 & $7.04 \pm 0.14$ & $7.24 \pm 0.15$ & 0.33 & 0.83 \\
\hline LN ULF, $\mathrm{Ms}^{2}$ & $5.49 \pm 0.16$ & $5.67 \pm 0.17$ & 0.44 & $5.23 \pm 0.16$ & $5.41 \pm 0.13$ & 0.39 & 0.22 \\
\hline LN VLF, $\mathrm{Ms}^{2}$ & $6.48 \pm 0.16$ & $6.38 \pm 0.18$ & 0.68 & $6.18 \pm 0.14$ & $6.35 \pm 0.13$ & 0.38 & 0.89 \\
\hline LN LF, $\mathrm{Ms}^{2}$ & $5.46 \pm 0.20$ & $5.31 \pm 0.23$ & 0.62 & $5.48 \pm 0.18$ & $5.65 \pm 0.18$ & 0.51 & 0.24 \\
\hline $\mathrm{LN} \mathrm{HF,} \mathrm{Ms}^{2}$ & $4.68 \pm 0.22$ & $4.82 \pm 0.22$ & 0.65 & $4.78 \pm 0.19$ & $5.03 \pm 0.20$ & 0.37 & 0.49 \\
\hline LF $n, \%$ & $66.7 \pm 2.39$ & $60.8 \pm 3.0$ & 0.13 & $65.2 \pm 2.16$ & $63.5 \pm 2.15$ & 0.58 & 0.45 \\
\hline HF n, $\%$ & $33.3 \pm 2.39$ & $39.2 \pm 3.0$ & 0.13 & $34.7 \pm 2.15$ & $36.5 \pm 2.15$ & 0.56 & 0.45 \\
\hline $\mathrm{LF} / \mathrm{HF}$ & $2.86 \pm 0.20$ & $2.03 \pm 0.23$ & $0.008 *$ & $2.46 \pm 0.21$ & $2.22 \pm 0.18$ & 0.39 & 0.51 \\
\hline \multicolumn{8}{|c|}{ Night } \\
\hline LN TP, Ms $^{2}$ & $7.20 \pm 0.15$ & $7.38 \pm 0.18$ & 0.45 & $7.18 \pm 0.15$ & $7.52 \pm 0.15$ & 0.11 & 0.55 \\
\hline LN ULF, $\mathrm{Ms}^{2}$ & $5.30 \pm 0.17$ & $5.57 \pm 0.18$ & 0.30 & $5.16 \pm 0.14$ & $5.46 \pm 0.13$ & 0.12 & 0.61 \\
\hline LN VLF, Ms $^{2}$ & $6.43 \pm 0.15$ & $6.64 \pm 0.18$ & 0.37 & $6.35 \pm 0.14$ & $6.65 \pm 0.15$ & 0.15 & 0.97 \\
\hline LN LF, Ms $^{2}$ & $5.51 \pm 0.17$ & $5.53 \pm 0.26$ & 0.95 & $5.65 \pm 0.17$ & $5.98 \pm 0.19$ & 0.20 & 0.16 \\
\hline LN HF, мs $^{2}$ & $5.00 \pm 0.22$ & $5.17 \pm 0.23$ & 0.60 & $5.06 \pm 0.19$ & $5.48 \pm 0.19$ & 0.12 & 0.30 \\
\hline LF n, $\%$ & $60.8 \pm 2.74$ & $58.8 \pm 3.19$ & 0.64 & $62.7 \pm 2.26$ & $61.5 \pm 2.35$ & 0.71 & 0.49 \\
\hline HF n, $\%$ & $39.2 \pm 2.74$ & $41.2 \pm 3.19$ & 0.64 & $37.3 \pm 2.26$ & $38.5 \pm 2.35$ & 0.71 & 0.49 \\
\hline $\mathrm{LF} / \mathrm{HF}$ & $2.26 \pm 0.37$ & $1.81 \pm 0.22$ & 0.30 & $2.27 \pm 0.22$ & $2.09 \pm 0.19$ & 0.54 & 0.34 \\
\hline
\end{tabular}

$*_{\text {- }} p<0,05$ (LF - power in the diapason of low frequencies; HF - power in diapason of high frequencies; LF/HF - ratio of low frequency to high frequency ingredients of spectrum, TP-common spectral power)

\section{Dynamics of HRV geometry indicators on background of therapy}

In Group 1, the the analysis of HRV geometry indicators revealed a non-significant increase in IC (by $15.9 \%$ ), HRV TI (by $11.4 \%$ ), and Mo (by $3.5 \%$ ) values in daytime, as well as reduction of AMo by $11.4 \%$ in comparison with initial values (Fig.1). In contrast, the value of IC was reduced by $15.3 \%$ at night. A similar trend was noted in Group 2, except for a difference in the daytime (by $10.3 \% ; \mathrm{P}=0.002$ ) and nightly hours (by 14.8\%; $\mathrm{P}=0.000$ ), including Mo and HRV TI (by $23.6 \%$; $\mathrm{P}=0.02$ ), namely, there were statistically significant changes compared to baseline.

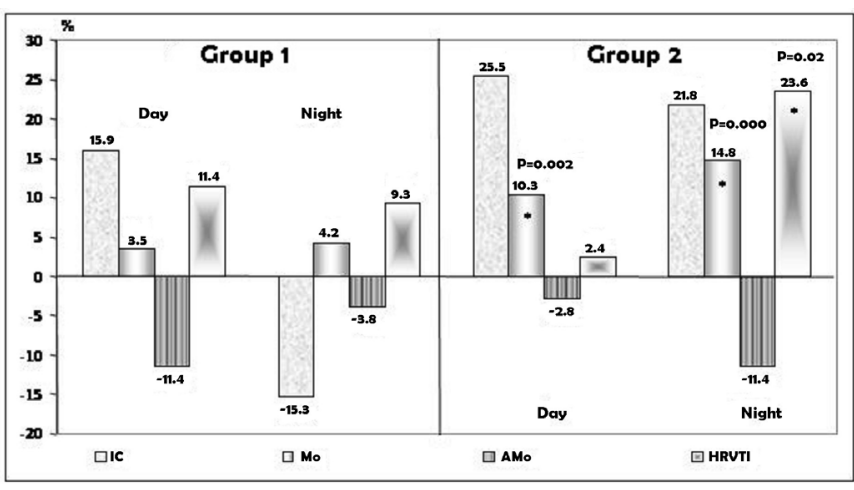

Fig.1. IC-index of centralization, stage of centralization of the control of $\mathrm{HR}$; $\mathrm{Mo}$ -mode, occurred mostly frequent in this dynamic line, value of cardio interval; AMo-amplitude of Mo, reflected stabilizing effect of the centralization of HR; HRVTI - the integral of spectrum of distribution rate related to the maximum distribution density. 


\section{Discussion}

At the early stage of AMI (2-3 days), HRV has important prognostic information and facilitates prognosis of later mortality [8]. Recent research has proved that the speed of the HRV restoration after AMI is correlated to future risk [9]. In the first 48 hours of AMI, according to our results, a strong trend in reduction of SDNN value in the daytimeand at night, which was marked in patients of both groups, reflects an unfavorable prognosis [2]. An effort to influence on HRV in persons who had AMI previously is based on multiple observations, which revealed a higher mortality of post-infarction patients with a significant reduction of HRV (SDNN $<50 \mathrm{mc}$ ) $[10,11]$. Current data on the efficacy of using beta-blockers on patients with T2DM are limited, despite the statistically significant increase in the HRV background of beta-blockers. Identified changes seemed to be moderate, mainly at the expense of an increase in LF value $[12,13]$. The mechanism of the Omega-3-PUFA effect on the HRV has not been sufficiently studied; however, its efficiency has been confirmed in some investigations [7,14]. We encountered this problem during our study. Standard therapy, including the usage of beta-blocker bisoprolol during the first seven days AMI, did not result in any important change in the HRV time-domain parameters (SDNN: $41.6 \pm 2.42 \mathrm{~ms}$, RMSSD: $26.6 \pm 2.77 \mathrm{~ms}$ in the daytime and SDNN: $45.9 \pm 2.15$ ms, RMSSD: $30.3 \pm 3.14 \mathrm{~ms}$ at night).

The clinical state of patients required an increase in receiving an average dose of bisoprolol from $3.85 \pm 0.37$ to $4.34 \pm 0.46 \mathrm{mg} / \mathrm{day}$, which also had no significant effect on the parameters of geometry or the spectral domain of HRV. The statistically significant reduction of the ratio LF/HF in the patients receiving the standard therapy could be explained by the fact that they received higher doses of bisoprolol in comparison to Group 2, which caused a higher level of sympathetic blockade. However, these higher doses did not affect the parasympathetic section of nervous system. On the contrary, the reception of the addition of the high dose of omega-3-PUFA (Omacor, $4 \mathrm{~g}$ /day) to the standard therapy resulted in a significant increase in SDNN (from 38.4 \pm 1.42 $\mathrm{ms}$ to $44.0 \pm 1.82 \mathrm{~ms}(\mathrm{P}=0.02)$, RMSSD from $24.4 \pm 1,36 \mathrm{~ms}$ to $33.8 \pm 2.88 \mathrm{~ms} \quad(\mathrm{P}=0.004)$, $\mathrm{pNN} 50 \%$ (from $4.01 \pm 0.81 \%$ to $7.16 \pm 1.03 \%(\mathrm{P}=0.002)$ values in the daytime, as well as SDNN from $41.9 \pm 1.80 \mathrm{~ms}$ to $50.0 \pm 1.93 \mathrm{~ms}(\mathrm{P}=0.003)$ and RMSSD from $30.2 \pm 1,27 \mathrm{~ms}$ to $39.0 \pm 2.77 \mathrm{~ms} \quad(\mathrm{P}=0.005)$ at night. The dose of receiving bisoprolol was increased non-significantly (from $3.47 \pm 0.19$ to $3.95 \pm 0.32 \mathrm{mg} /$ day). According to the literature, an increase in SDNN, RMSSD, pNN50 values, as well as Mo and HRVTI, and reduction of LF/HF indicates an increased activity of the parasympathetic nervous system. These features lead to the normalization of the autonomic imbalance $[1,3]$. The results obtained were also confirmed with geometry indicators of HRV in Group 2: an increased Mo (from 816.0 20.1 to $900.0 \pm 17.3 \mathrm{~ms}(\mathrm{P}=0.002)$ in daytime and HRV TI (from 16.1 \pm 0.93 to $19.9 \pm 1.27$ $(\mathrm{P}=0.02)$ at night. The predisposition to the occurrence of life-threatening HRV disorders relates directly to the increase of sympathetic activity or reduced vagus function that characterized an unfavorable nearest prognosis in patients with AMI [15-19]. The main purpose of our study was to assess the efficacy of a high dose of omega-3-PUFA (4g/day) in addition to the standard therapy on the HRV parameters in patients at early stage of AMI and concomitant T2DM. Our study has demonstrated that using Omega-3-PUFA $4 \mathrm{~g} /$ day had a positive and statistically significant effect on the HRV indicators, namely, the parasympathetic part of the vegetative nervous system. Additionally, this regimen allowed the occurrence of unfavorable complications to be reduced, even in the first seven days of the treatment, and had an impact on the further life predictions.

\section{Conclusion}

1. In the patients with AMI and concomitant T2DM, there were significant changes in the main parameters of HRV that reflected the decrease in the activity of the parasympathetic nervous system (SDNN, RMSSD, pNN50, Mo HRVTI) and an increase in the activity of the sympathetic nervous system (LF/HF, AMo).

2. Use of omega-3-PUFA in addition to standard therapy from the first hours of AMI allowed stabilization of the parasympathetic-sympathetic imbalance and, as a consequence, reduction of the risk of AMI complications.

\section{Competing interests}

The authors declare that they have no competing interests.

\section{References}

1. Task Force of the European Society of Cardiology and the North American Society of Pacing and Electrophysiology. Heart rate variability. Standards of measurement, physiological interpretation, and clinical use. Eur Heart J 1996; 17(3):354 81.

2. Yavelov IS, Deev AD, Travina EE, Gracianskiy NA. Prognostic value of the mean frequency of contractions and heart rate variability assessed for short time under the standard conditions at the early terms of myocardial infarction. Russ Cardiol J 1999; 6:6-13.[Article in Russian].

3. Kiryachkov YY, Khmelevskiy YM, Voroncova EV. Computed analysis of heart rate variability: technique, interpretation, clinical use. Anaesthesiology J 2000; (2):56-62. [Article in Russian].

4. Yavelov IS, Zuykov YA, Deev AD, Travina EE, Gracianskiy NA, Averkov OV, Vaulin NA. Experience of study on heart rate variability in acute coronary syndromes. Russ Cardiol J 1999; (1):3-10. [Article in Russian].

5. Derad L, Otterbein A, Molle M, Petrowsky R, Born $\mathrm{J}$, Fehm $\mathrm{H}$. The angiotensin converting enzyme inhibitors fosinopril and enalapril differ in their central nervous effects in humans. J Hypertens 1996; 14(11):1309-1315.

6. Dmitryuk PB. Effect of propafenon on the dynamics of rhythmographic parameters and quality of life in the patients with extrassystolic arrhythmia. Russ Cardiol J 1997; 37(3): 47-50. [Article in Russian].

7. GISSI-Prevenzione Investigators (Gruppo Italiano per lo Studio della Sopravvivenza nell'Infarto miocardico). Dietary supplementation with n-3 polyunsaturated fatty acids and vitamin $\mathrm{E}$ after myocardial infarction: results of the GISSI- 
Prevenzione trial. Lancet 1999; 354(9177):447-55.

8. Singer $\mathrm{DH}$, Ori $\mathrm{Z}$. Changes in heart rate variability associated with sudden cardiac death. In: Malik M, Camm AJ, Eds. Heart rate variability. Armonk, NY: Future Publishing Co 1995:429-48.

9. Binkley PF, Haas GJ, Starling RC, Nunziata E, Hatton PA, Leier CV, et al. Sustained augmentation of parasympathetic tone with angiotensin- converting enzyme inhibition in patients with congestive heart failure. J Am Coll Cardiol 1993; 21(3):655-61.

10. Bigger JTJr, Fleiss JL, Steinman RC, Rolnitzky LM, Kleiger RE, Rottman JN. Frequency domain measures of heart period variability and mortality after myocardial infarction. Circulation 1992; 85(1):164-71.

11. Guzzetti S, Dassi S, Pecis M, Casati R, Masu AM, Longoni $\mathrm{P}$, et al. Altered pattern of circadian neural control of heart period in mild hypertension. J Hypertens 1991; 9(9):831-8.

12. Binkley PF, Nunziata E, Haas GJ, Nelson SD, Cody RJ. Parasympathetic withdrawal is an integral component of autonomic imbalance in congestive heart failure: demonstration in human subjects and verification in a paced canine model of ventricular failure. J Am Coll Cardiol 1991; 18(2):464-72.

13. Townend JN, West JN, Davies MK, Littles W.A. Effect of quinapril on blood pressure and heart rate in congestive heart failure. J Am Cardiol 1992; 69(19):1587-90.

14. Burr M.L. Reflections on the diet and reinfarction trial (DART). Eur Heart J 2001; 3(suppl D):75-78.

15. Corr PB, Yamada KA, Witkowski FX. Mechanisms controlling cardiac autonomic function and their relation to arrhythmogenesis. In: Fozzard HA, Haber E, Jennings RB, Katz AM, Morgan HE, Eds. The Heart and Cardiovascular System. New York: Raven Press; 1986:1343-1404.

16. Levy MN, Schwartz PJ, Eds. Vagal control of the heart: Experimental basis and clinical implications. Armonk, NY: Future Publishing Co; 1994.

17. Schwartz PJ, Priori S.G. Sympathetic nervous system and cardiac arrhythmias. In: Zipes DP, Jalife J, Eds. Cardiac Electrophysiology: From Cell to Bedside. Philadelphia, PA: WB Saunders Company; 1990:330-343.

18. Lanza G.A, Pedrotti P, Rebuzzi AG, Pasceri V, Quaranta $\mathrm{G}$, Maseri A. Usefulness of the addition of heart rate variability to Holter monitoring in predicting in-hospital cardiac events in patients with unstable angina pectoris. Am J Cardiology 1997; 80(3):263-7.

19. McCance AJ, Thompson PA, Forfar JC. Increased cardiac sympathetic nervous activity in patients with unstable coronary heart disease. Eur Heart J 1993;14(6):751-7. 